\title{
Measuring local competitiveness: comparing and integrating two methods PCA and AHP
}

\author{
Katarzyna A. Kurek ${ }^{1}$ (D) Wim Heijman ${ }^{1,3}$. Johan van Ophem ${ }^{1}$. Stanisław Gędek ${ }^{2}$. \\ Jacek Strojny ${ }^{2}$
}

Accepted: 9 June 2021 / Published online: 21 June 2021

(c) The Author(s) 2021

\begin{abstract}
This article discusses two methods to measure the concept of local competitiveness: Principal Component Analysis (PCA) and Analytical Hierarchy Process (AHP). The goal of this analysis is to determine whether these two methods used in social sciences research lead to comparable model results. By non-parametric tests we show that there is a significant correlation between the PCA and AHP local competitiveness indexes. Thereafter, a developed mixed method examination of whether the methods can be used interchangeably is presented and illustrated with detailed examples of two mixed approaches. The mixed method confirms the correlation between the PCA and AHP models. However, the mixed modelling results indicate the utility of the PCA in the situation of a multicriteria local competitiveness data examination.
\end{abstract}

Keywords Local competitiveness $\cdot$ Multivariate models $\cdot$ Multicriteria decision-making method · Socioeconomic indicators · Principal Component Analysis · Analytical Hierarchy Process $\cdot$ Non-parametric testing

\section{Introduction}

The choice of a research method is determined by the type of data or its collection systems. The mixed method approach depends on the type of the study's research question and moreover reflects on the subjective and objective knowledge of the research problem according to Tashakkori and Teddlie (2010). Sharp et al. (2012) point to the utility of mixed methods in mostly in the decision making process studies. A multicriteria decision-making method in its principle analyses sets of variables simultaneously on different observations. This paper tackles the concept a local competitiveness model, presented in

Katarzyna A. Kurek

katarzyna.kurek@wur.nl

1 Wageningen University and Research, Building 201, Hollandseweg 1, 6706 KN Wageningen, The Netherlands

2 Rzeszów University of Technology, Building S, Aleja Powstańców Warszawy 10, 35-959 Rzeszów, Poland

3 Czech University of Life Sciences, Kamýcká 129, 16500 Prague, Czech Republic 
the studies (Kurek et al. 2020a, 2020b), referred further as study 1 and study 2. By using these examples a multivariate data model analysis is presented. Two multifactor methods i.e. Principal Component Analysis (PCA) and Analytical Hierarchy Process (AHP) were applied to build a local competitiveness models in both studies. These procedures led to the establishment of local competitiveness indexes for the analysed municipalities in Poland, which were used for further econometric analysis. In this article we focus on the structure of the local competitiveness models developed by the PCA and AHP methods. Both the PCA and AHP methods enabled the computation of a singular competitiveness index, which measures the level of local competitiveness. This index allows for the observation of trends in development over time, and the comparison of competitiveness levels among the sampled municipalities. Approaches to a single competitiveness index used in regional and local studies can be found in works by: Huovari et al. (2002), Plummer et al. (2014), Huggins (2003), Ozaslan et al. (2006), Bronisz et al. (2008), Bulu (2011), Dijkstra et al. (2011), Lengyel and Rechnitzer (2013), Makštutis at el. (2012), Sáez and Periáñez (2015), Trisnawati et al. (2008), with attention given to the weighting system decisive to the model outcome.

An essential element of regional competitiveness is the presence of natural resources (Gross and Ringbeck, 2008; Porter, 2003, 2008; Rutkauskas, 2008) that allow for infrastructural development (Camagni and Capello, 2013; Eskelinen et al. 2002; Palei, 2015). It supports our research assumption about the positive relation between local competitiveness and geothermal resources in the study 1 (Kurek et at. 2020a) and study 2 (Kurek et al. 2020b). Nevertheless, the literature does not point to one, exclusive approach in defining local competitiveness. In the two studies about the impact of geothermal resources on local competitiveness, we developed two approaches to construct a local competitiveness index, a PCA and a AHP model. Both indexes were based on the same indicator's dataset input, i.e. secondary data collected from the same statistical data source. Still, the value of the indexes delivered by the PCA and AHP differ due to the weight structures that each method employs.

Although there are various techniques for normalizing multicriteria criteria and determining their weights, the construction of a local indicators-based model in the referenced geothermal papers has been tackled by two methods that are different in nature. The PCA, as a multivariate analysis, built the local model by transforming indicators without losing information and by identifying new variables with greater meaning. As a multicriteria decision-making method predominantly qualitative, the AHP evaluated the local indicators by asking experts and applied priority scales into the construction of the model. Yet, both techniques result in a weights model applicable to the criteria that are examined.

The research question of this study is how comparable are the results yielded by the PCA and AHP methods in the situation of secondary data? We draw this research question from applying the two approaches to the similar problems in the both referred studies. The two models based on the same socioeconomic secondary data delivered two indexes i.e. the measures of local competitiveness or development. A statistical comparison of the indexes rankings constitutes the core analysis of this paper. By using statistical procedures, we aim to methodically determine whether PCA and AHP results are comparable, or whether the methods can be used interchangeably for a phenomenon of socioeconomic data. This comparison of both methods is legitimate if we find a significant relationship between the results obtained by the PCA and AHP. To explore the comparison, we propose mixed weights modelling, which is an experimental method in the context of our research problem and the methods' specificities. Such a practical approach is not yet found in the existing methodological literature and related socioeconomic studies. 
The theoretical framework of this article sits in the nature of the epistemology. This discipline is driven by the process of knowledge and seeking validation for already known ideas. In its variation, it also discusses the criteria to corroborate a concept (Bunge 2001). Modern interpretation of epistemology in social sciences includes areas of research methods and methodology. Throughout the analysis the research question is addressed by the justification of the methods selection and the results. The design of a mixed method refers to the motivation for their integration and to the so-called pragmatic epistemology. In this article, the purpose for integration derives from the data structure and assumed convergent findings delivered by the two methods. Moreover, the motivation behind developing the mixed methods approach is also influenced by the paradigm of choices emphasized by Patton (1990). His concept refers to the choice of a research method determined by the type of research problem rather than by methodological appropriateness. In this way, the mixed methods approach serves for better analysis of the core of our study, i.e. the comparison of two multicriteria methods with different assumptions. According to the paradigm of choices, the research question and context dictate the choice of appropriate techniques and the degree of mixing methods in order to be able to answer the research question, argues Mason (2006).

This introduction explaining the purpose of the paper is followed by the presentation of the developed local competitiveness models. Then, the analysis of the models takes place. Next, the used methods are explained. The new, mixed approach of presenting two mixed models is proposed further with the section on outcomes testing. A section with conclusions and discussion closes the paper.

\section{The PCA and AHP local competitiveness models}

The form of a competitiveness model is dependent on the composition of the variables that build it. Thus, the selection of the competitiveness variables is a decision-making process. It mainly concerns the dataset that is available and comparable at the given level and at the same time reflects its competitive performance. In the case of our research problem, the dataset had to reflect the local competitiveness indicators at the municipality level. The models of local competitiveness in the studies 1 and 2 concerned a selection of municipalities in Poland. The group of municipalities was conditioned by the research assumptions in the two studies and limited to 63 municipal units in Poland. The concept of local competitiveness model followed the local competitiveness definition of Storper (1997) that points at the local potential of sustaining an attractive and stable environment for market growth and providing standards of living for those who participate in it. Therefore, the design of the indicators model encompasses socioeconomic data representing local economic condition and development potential. Local socioeconomic data used in the studies 1 and 2 was collected from a homogenous source - the Local Data Bank, which is a section of the Central Statistical Office in Poland ${ }^{1}$ at the level of NUTS $5^{2}$ for the years 1995-2017. This source allowed for the assurance of data coherency and comparability for the observed municipalities. From the available and coherent socioeconomic data, the local

\footnotetext{
1 Selection of available and consistently collected socioeconomic indicators sourced in the Central Statistical Office of Poland (https://bdl.stat.gov.pl/BDL/start).

${ }^{2}$ NUTS is the Eurostat's Nomenclature of Territorial Units for Statistics. In Poland, NUTS 5 corresponds with the municipal administrative unit.
} 


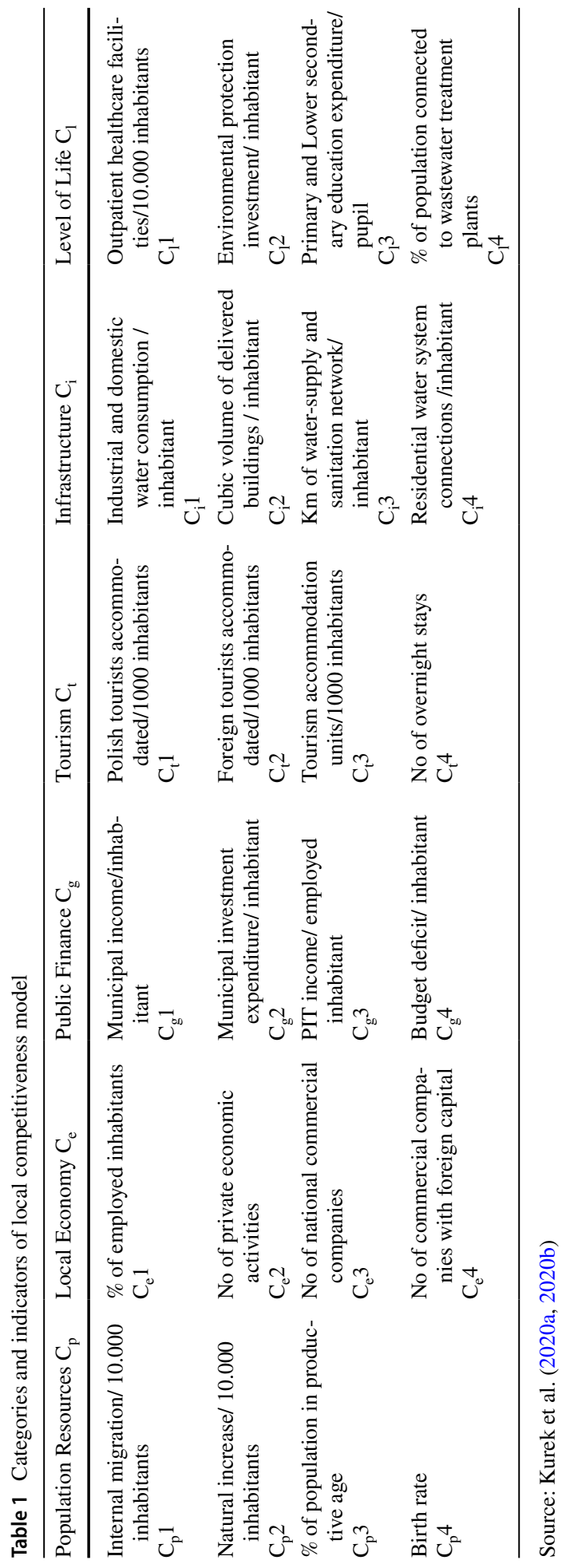


Table 2 The AHP computed municipality competitiveness indicators weights model

\begin{tabular}{|c|c|c|c|c|c|}
\hline \multicolumn{6}{|c|}{ Weights of categories } \\
\hline${ }^{*} \mathrm{wC}_{\mathrm{p}}=0.14$ & $\mathrm{wC}_{\mathrm{e}}=0.24$ & $\mathrm{wC}_{\mathrm{g}}=0.12$ & $\mathrm{wC}_{\mathrm{t}}=0.17$ & $\mathrm{wC}_{\mathrm{i}}=0.19$ & $\mathrm{wC}_{1}=0.14$ \\
\hline \multicolumn{6}{|c|}{ Weights of subcategories } \\
\hline $\mathrm{wC}_{\mathrm{p}} 1=0.26$ & $\mathrm{wC}_{\mathrm{e}} 1=0.23$ & $\mathrm{wC}_{\mathrm{g}} 1=0.16$ & $\mathrm{wC}_{\mathrm{t}} 1=0.26$ & $\mathrm{wC}_{\mathrm{i}} 1=0.16$ & $\mathrm{wC}_{1} 1=0.18$ \\
\hline $\mathrm{wC}_{\mathrm{p}} 2=0.28$ & $\mathrm{wC}_{\mathrm{e}} 2=0.22$ & $\mathrm{wC}_{\mathrm{g}} 2=0.40$ & $\mathrm{wC}_{\mathrm{t}} 2=0.28$ & $\mathrm{wC}_{\mathrm{i}} 2=0.36$ & $\mathrm{wC}_{1} 2=0.27$ \\
\hline $\mathrm{wC}_{\mathrm{p}} 3=0.25$ & $\mathrm{wC}_{\mathrm{e}} 3=0.30$ & $\mathrm{wC}_{\mathrm{g}} 3=0.24$ & $w_{t} 3=0.19$ & $\mathrm{wC}_{\mathrm{i}} 3=0.26$ & $\mathrm{wC}_{1} 3=0.34$ \\
\hline $\mathrm{wC}_{\mathrm{p}} 4=0.21$ & $\mathrm{wC}_{\mathrm{e}} 4=0.25$ & $\mathrm{wC}_{\mathrm{g}} 4=0.20$ & $\mathrm{wC}_{\mathrm{t}} 4=0.27$ & $\mathrm{wC}_{\mathrm{i}} 4=0.22$ & $\mathrm{wC}_{1} 4=0.21$ \\
\hline
\end{tabular}

*w- weight, C- category, source: Kurek et al. (2020a)

Table 3 The PCA computed municipality competitiveness indicators weights model

\begin{tabular}{|c|c|c|c|c|c|c|c|}
\hline \multicolumn{8}{|c|}{ Principal components } \\
\hline${ }^{*} \mathrm{wC} 1=0.27$ & $\mathrm{wC} 2=0.17$ & $\mathrm{wC} 3=0.15$ & $\mathrm{wC} 4=0.08$ & $\mathrm{wC} 5=0.09$ & wC6 $=0.09$ & $\mathrm{wC} 7=0.08$ & $\mathrm{wC} 8=0.07$ \\
\hline \multicolumn{8}{|c|}{ Factor loadings } \\
\hline $\mathrm{wC}_{\mathrm{p}} 4=0.11$ & $\mathrm{wC}_{\mathrm{g}} 3=0.49$ & $\mathrm{wC}_{\mathrm{t}} 1=0.35$ & $\mathrm{wC}_{\mathrm{p}} 1=0.30$ & $\mathrm{wC}_{\mathrm{p}} 2=0.64$ & $\mathrm{wC}_{\mathrm{g}} 2=0.44$ & $\mathrm{wC}_{\mathrm{p}} 3=0.77$ & $\mathrm{wC}_{\mathrm{t}} 4=0.34$ \\
\hline $\mathrm{wC}_{\mathrm{e}} 1=0.11$ & $\mathrm{wC}_{1} 3=0.51$ & $\mathrm{wC}_{\mathrm{t}} 2=0.30$ & $\mathrm{wC}_{\mathrm{i}} 2=0.28$ & $\mathrm{wC}_{\mathrm{i}} 3=0.36$ & $\mathrm{wC}_{\mathrm{g}} 4=0.56$ & & $\mathrm{wC}_{\mathrm{i}} 1=0.31$ \\
\hline $\mathrm{wC}_{\mathrm{e}} 2=0.13$ & & $w_{\mathrm{t}} 3=0.35$ & $\mathrm{wC}_{\mathrm{i}} 4=0.42$ & & & & $\mathrm{wC}_{1} 2=0.35$ \\
\hline \multicolumn{8}{|l|}{$\mathrm{wC}_{\mathrm{e}} 3=0.15$} \\
\hline \multicolumn{8}{|l|}{$\mathrm{wC}_{\mathrm{e}} 4=0.14$} \\
\hline \multicolumn{8}{|l|}{$\mathrm{wC}_{\mathrm{g}} 1=0.12$} \\
\hline \multicolumn{8}{|l|}{$\mathrm{wC}_{1} 1=0.09$} \\
\hline $\mathrm{wC}_{1} 4=0.15$ & & & & & & & \\
\hline
\end{tabular}

*w-weight, $C$-component, source: Kurek et al. (2020b)

competitiveness indicators were constructed in theoretical reference to work of: Malecki (2004), Olewiler (2006), Pires et al. (2014), Scipioni et al. (2009), Strojny (2015). Hence, Table 1 depicts the indicators that compose the local competitiveness model used in both studies.

This model pursued by the PCA and AHP methods resulted in the local competitiveness indexes that we aim to compare. As discussed, although the input model data was the same in both studies, we obtained different values of the local competitiveness indexes. The PCA and AHP indexes values and the data they are built of is stored in the Mendeley repository with a detailed explanation (Kurek 2020).

Hence, the element that differentiated these results is the weights that both methods yield in reference to the model indicators. These weights constitute the system decisions about the importance of each of the competitiveness indicators that were further synthetized in the form of an index. Where the PCA as a factor analysis regrouped the original structure of the local competitiveness model (Table 1), the AHP expert method did not change its presumed structure (Table 1). Experts followed the given model, assessing the weights according to their own judgements. Tables 2 and 3 present the obtained weights of the local competitiveness indicators from each method. The labels of the indicator's weights refer to the classification indicators from Table 1.

We observe that the PCA method restructured the Table 1 local competitiveness model by regrouping the indicators into eight principal components (Table 3 ). The original structure of the proposed model is kept in the AHP method's weights assessment (Table 2). 
Therefore, the composition of weights is here the main determinant of the proposed local competitiveness model in both studies. Since the two local competitiveness indexes do not represent a normal distribution, their comparison refers to non- parametric testing. As our study aims to find out how the results delivered by both methods are comparable, we seek correlations between them. We propose to address the study objective by testing the correlations of the rankings of the 63 municipalities built according to the PCA and AHP competitiveness index scores. The number of municipalities observed is the same as in the related studies 1 and 2 i.e. the geothermal municipalities and associated benchmark municipalities. Creating rankings due to the index score is the preferred approach since local competitiveness is not measured at an absolute level. This arrangement allows for the comparison of the relative position of a municipality observation in the ranking due to the index score. The index value itself does not indicate the competitiveness of a municipality.

Considering the difference in the local competitiveness model design and in order to compare the methods, we test the correlations between the two competitiveness indexes. The correlations are to indicate the assumed convergence of indexes. Using correlations, we are able to measure the degree to which the two indexes move in relation to each other i.e. their association. We do not seek causal relationship between the local competitiveness indexes, but an observation as to whether and how strongly the two index variables are related. In the case of an acceptable correlation, it can be assumed that the methods can be used interchangeably when examining local competitiveness. The next section discusses the results of correlation testing that use average competitiveness indexes as the model variables.

\section{Comparison of the PCA and AHP local competitiveness models}

The examination of the correlation between the two local competitiveness indexes answers the research question about the comparability of the two methods, in the case of a determined set of local socioeconomic indicators used for the local competitiveness models. Therefore, the testing is intended to determine the strength of the assumed relation between the PCA and AHP generated models. The two competitiveness indexes of the examined 63 municipalities, calculated for the years 1995-2017 do not represent the normal distribution (see Kurek 2020). Hence, the interpretation about the municipalities' competitiveness includes a relative competitive position within the range of municipalities. The local competitiveness indexes of the municipalities cannot be interpreted numerically. The interpretation lies in comparing the value of the indexes within the selected batch of municipalities on an ordinal scale. That is why the non-parametric tests ranking the municipalities' competitiveness indexes can answer our research problem. However, for the purpose of our testing we apply the final rankings of the selected 63 municipalities according to PCA and AHP, built as an average ranking position for the observed period 1995-2017. The compilation of the rankings of average municipal competitiveness are presented in the study of (Kurek 2020).

Siegel (1957) discusses the usefulness of the non-parametric tests for cases of ordering, classification, or rankings. Non-parametric methods, unlike classical statistical methods, do not need to estimate the parameters of a predetermined random variable distribution in the population. The non-parametric model's robustness requires a larger sample size to draw conclusions with the same degree of confidence. Moreover, non-parametric models differ from parametric ones in that the model structure is not specified a priori but is instead 
Table 4 Cross tabs correlation calculation for the PCA and AHP local competitiveness indexes rankings

\begin{tabular}{lllll}
\hline & Value & $\begin{array}{l}\text { Asymptotic Stand- } \\
\text { ard Error }^{\mathrm{a}}\end{array}$ & Approximate T $^{\mathrm{b}}$ & $\begin{array}{l}\text { Approximate } \\
\text { Significance }\end{array}$ \\
\hline Ordinal by Ordinal & & & & .000 \\
Kendall's tau-c & .390 & .079 & 4.907 & .000 \\
Gamma & .390 & .079 & 4.907 & $.000^{\mathrm{c}}$ \\
Spearman Correlation & .542 & .098 & 5.037 & \\
N of Valid Cases & 63 & & & \\
\hline
\end{tabular}

${ }^{a}$ Not assuming the null hypothesis

${ }^{\mathrm{b}}$ Using the asymptotic standard error assuming the null hypothesis

${ }^{\mathrm{c}}$ Based on normal approximation

source: SPSS stats 25 own elaboration

determined from the data type (Anderson 1961). This is illustrated by our two cases of local competitiveness models, which depend on the determined data selection.

To express the correlation between two variables, a correlation coefficient is calculated. The three most common non-parametric correlation coefficients are: Spearman's R, Kendall's tau and Gamma (Bagdonavicius et al. 2013). When calculating Spearman's $\mathrm{R}$, it is assumed that the considered variables were measured at least on the ordinal (ranked) scale, i.e. that individual observations can be arranged in two ordered series. The statistical power of Kendall's tau is similar to Spearman's R coefficient. However, the values of both coefficients usually do not coincide, because their logical foundations and calculation formulas differ significantly. Siegel and Castellan (1988) express the relationship between these two measures in the form of inequalities: $-1 \leq 3$ $*$ Kendall's tau $-2 *$ Spearman's $\mathrm{R} \leq 1$. More importantly, these coefficients have different interpretations. Spearman's R coefficient can be treated similarly to Pearson's linear correlation coefficient, i.e. in terms of the percentage of variability explained. The difference is that Spearman's R is calculated based on rank, whereas the Kendall's tau coefficient is based on the probability, i.e. the difference between the probability, that two variables are in the same order within the observed data and the probability that their order is different. In our examination we chose Kendall's tau-c for the correlations interpretation since it is used for rectangular tables and adjusts for tied ranks. Using the SPSS software version 25 we run the non-parametric correlation test for the local competitiveness indexes (stored in Kurek 2020) yielded by the PCA and AHP methods. The SPSS analysis includes the non-parametricity coefficients. Table 4 presents the test results.

Having observed the coefficients we argue that the two distributions are acceptably correlated. Therefore, the rankings obtained by the PCA and AHP methods are correlated according to the correlation coefficients scores. The quantitative relationship between the variables is statistically significant. These two methods that are different from each other in the assumptions and procedures show a clear correlation between the results obtained. We studied the same multivariate phenomenon of local competitiveness through the PCA and AHP procedures, which proved to be related to each other. Due to the obtained research results and their convergence, we argue that both methods can be used to analyse the multicriteria concept of local competitiveness. Thus, both decision-making methods are accepted in this comparative analysis. 
Although the PCA and AHP models used the same dataset, the weight system of each method is nevertheless responsible for the yielded correlation level. The next section analyses the weights generation in the principles of the PCA and AHP method. A mixed weights experiment is then carried out.

\section{The local competitiveness index by the PCA and AHP methods}

A multiple criteria research problem requires the identification and weighting of the criteria to allow research topics to be ranked on the basis of a composite score (Horton et al. 1993). These weights are further used to calculate a single measure of the overall contribution of each indicator to a combined set of objectives. Huggins (2003) points to the importance of weights in creating a competitiveness index. Weights represent their relative effectiveness as a performance measure, in particular illustrating the interrelationships between the input data and output indicator value. In both our model scenarios, the weights are determined by the PCA and AHP procedures (see Table 2 and Table 3). These weights models processed with the data of the Table 1 indicators deliver the synthetic local competitiveness index (see Kurek, 2020). Despite the same input data, the difference in the two index values is explained by the different weights models generated by the two methods. Therefore, the acceptable level of correlation of the PCA and AHP local competitiveness indexes (Table 4) results from the methods' assumptions regarding the weighting system.

\subsection{Principal Component Analysis local competitiveness index}

As a multifactor analysis, the Principal Component Analysis is particularly suited to examine a set of correlated variables in socioeconomic studies (Fabrigar and Wegener 2011; Jolliffe 1986; Taherdoost et al. 2014; Vyas and Kumaranayake 2006). The PCA represents a method that normalizes the data through compromise, further decomposing the data concentration into a set of new orthogonal variables i.e. the principal components ordered by the amount of variance that each component explains (Hervé Abdi and Williams 2010; Govaert 2013). The observation on each component is called the factor score and refers to the weight of a component in the new composition of the dataset. They are ordered by the amount of variance that each component explains. Further on, the method generates a coefficient by which each standardized original variable should be multiplied to get the component score - so-called factor loading. Therefore, the PCA weights model refers to the correspondence between the heterogenous sets of variables i.e. the importance of a dimension. Herve Abdi et al. (2013) explain in detail the PCA procedure of multicriteria data integration, with attention given to the weighting mechanism proposed by this method. In study 2 (Kurek et al. 2020b), the PCA computation (using the SPSS version 22), which includes the loadings of components exceeding the acceptable value of 0.5 , varimax with Kaiser rotation, and explained variance larger than $60 \%$ results in establishing the main components of the model for each of the tested municipalities. All of the Table 1 model variables met these assumptions, therefore the PCA analysis accepted all the 24 indicators. For each component and its variables, the PCA assesses the weights, i.e. the loadings, as well. Next, a standardized sums formula is applied. The formula is based in the aggregation procedure of the normalized competitiveness indicators from Table 1 applied to the PCA 
generated weights model of Table 3. As a normalization approach, the zero unitarization method (Kukula and Bogocz 2014) was applied. Therefore, the Formula 1 takes a form of:

$$
C I=\sum^{n} w C_{i}=w C_{i}\left(\sum_{i=1}^{n} w_{i} C i\right)
$$

where

$$
\sum_{i=1}^{n} w_{i}=1
$$

and

$$
\sum_{i=1}^{n} w_{i} i=1
$$

$w C_{i}$-weight of the component. $w_{i} C i$-weight of the loading. $i=1, \ldots, N$ (observation).

The application of the Formula 1 yields the synthetic local competitiveness indicator values presented in the dataset (Kurek 2020), with an average score shown for each of the examined 63 municipalities. The index takes a value from 1 to 0 , where 1 is the highest value. Such values arrangement generated by the method allows for further comparison techniques.

\subsection{Analytical hierarchy process local competitiveness index}

In study 1 (Kurek et al. 2020a) we operationalize local competitiveness with the help of experts. The Analytical Hierarchy Process created in the ' $70 \mathrm{~s}$ by Saaty is popular among the multicriteria decision-making methods (MCDM) with particular applications in assessing socioeconomic and management problems (Linkov and Moberg 2011; Saaty 1988, 2000; Subramanian and Ramanathan 2012). The benefits of engaging experts from the examined scientific subject are addressed in the works of Boulanger and Bréchet (2005), Cox et al. (2000), Kil et al. (2016), and Strojny and Heijman (2016), among others. The AHP procedure is based on a hierarchical modelling of the criteria and their sub criteria. Experts evaluate their relationship in pairs using the Saaty's 1-9 scale. On the basis of the significance analysis in a given pair made by experts, the weight of a particular indicator is assigned. An important element of the method is also the consistency of the comparison in the matrix determined by the Consistency Ratio coefficient (CR), where the internal consistency of experts' judgements is checked. We used the dedicated AHP software Super Decisions (version 3.2) to accept or reject the weighting of given indicators while considering the CR score. Work of (Kurek et al. 2020c) presents the AHP tool that was distributed to the experts. Resulting from the pair-wise comparisons, each model element receives a weight, specifically the weight of the model category (global), $w_{i}$, and the subcategory indicator weight (local), $w_{i} i$. The experts' judgements decompose the problem to a reciprocal matrix $(\mathrm{KxK})$ of $P$ criterions where numbers in each criterion pair $\mathrm{p}_{\mathrm{i}}$ and $\mathrm{p}_{\mathrm{j}}$ to represent a ratio $\left(\mathrm{p}_{\mathrm{i}} / \mathrm{p}_{\mathrm{j}}\right) / 1$ (Oddershede et al. 2007; Saaty 1988). According to the AHP methodology, weights in each category sum up to 1 (or 100\%) since the elements from the same level are compared and weighted relative to each other. Therefore, a weight is interpreted from the significance of an indicator in the experts' opinion. Table 2 illustrates 
the obtained weights for the Table 1 municipality indicators. The same aggregation procedure of Formula 1 as in the PCA weight model was used, resulting in the normalised local competitiveness indexes for the 63 examined municipalities. They place in the $0-1$ range, where 1 represents the highest score of a municipality competitiveness throughout the observed time period. Dataset of Kurek (2020) contains the set of these indexes as well as the average score of the local competitiveness indexes from the observed period that is used in our testing.

\subsection{PCA and AHP structure modelling characteristics}

Where the PCA method seeks covariance between a practically unrestricted number of components, the AHP technique uses pair-wise relative comparison between each model indicators. Due to this fact, the AHP weights assignment is more complicated if the quantity of indicator pairs increases. Additionally, assessing experts as per the method requirement is the subjective decision of a scholar that decides to use the AHP (Ishizaka and Labib 2009; Maletič et al. 2016). The AHP method is particularly useful in the case of data inconsistency (Hartwich 1999) and in ranking alternatives regarding the criteria of social and sustainable development aspects (Alphonce 1997); but it does not have inbuilt techniques to indicate an optimal model structure. Therefore, the AHP permits assumptions whereas the PCA in its rigorous, statistical procedure eliminates the inconsistent model elements (Palese 2018). It indicates that the AHP method follows a presumed data or problem structure (Macharis et al. 2004). It is opposite to the PCA, which decomposes a data model (Herve Abdi et al. 2013) and its ability to rotate simplifies and restructures a model (Kim and Muller 1978). The different approaches to the hierarchisation of the two model's components and their weights accordingly, can explain the moderate results of the local competitiveness indexes correlations (Table 4). This observation provides room for a mixed method experiment that is based in the strengths of both methods and their weaknesses of weighting model indicators, and at the same time explores the obtained correlation results. In this paper, we seek an answer to the question of whether the results of both methods deliver comparable knowledge about a given phenomenon. The proposition of mixed modelling can support analysing the role of the weights structures that the PCA and AHP deliver.

\section{Integration of the PCA and AHP methods}

As explained, the decision about the local competitiveness model composition in the case of the two presented methods lies in the weights assessment procedure. The relationship found in Table 4 warrants further examination. We further explore the specifics of the two methods and introduce a mixed approach. This solution is applied as a cross check of the magnitude of the PCA and AHP weights models. The proposed mixed method local competitiveness model is to be validated using the same non-parametric testing. The new approach aims at finding out how the structure of both models impacts the obtained correlation results (Table 4). Moreover, the integration experiment intends to compare the weights structures delivered by either the statistical operations of the PCA or the ex-ante modelling of the AHP method. 
The integration is motivated in the cross validation of the model since both methods addressed a similar research question in the study 1 (Kurek et al. 2020a) and study 2 (Kurek et al. 2020b). Therefore, it's a check up on the two methods with different strengths that yield similar results. According to the pragmatic epistemology the consideration is how to integrate them to serve the research purpose. The pragmatism refers here to the question which of the two methods is more useful in the situation of a secondary data. In the epistemological approach, mixing methods reflects on the decision making process behind each model. The pragmatic epistemology leads to the paradigm of choices introduced by Patton. The said choice ponders on adopting the research method to circumstances, in this case, the data type and multicriteria analysis. Patton's paradigm of choices is particularly useful in the methodological discourse regarding the qualitative and quantitative methods appropriateness (Patton 2002; Johnson and Onwuegbuzie, 2004).

In the literature we find examples of studies on performance or comprehensive evaluations of projects where the PCA and AHP methods are integrated (see Komac 2006; Pawluszek and Borkowski 2017; Shi 2012; Subbaiah et al. 2011; Tee et al. 2017). The complementary application of the methods boils down mostly to the use of the PCA for establishing a data model of a given study or phenomenon, which is further evaluated by the AHP. The presented studies blend the PCA and AHP procedures in order to obtain a model of results.

We propose an integration of both methods to run an experimental comparison of the outcomes of local competitiveness modelling. Examples of PCA-AHP hybrids are found in operations research literature or project appraisal studies (see Feng and Wen 2011; Hoang et al. 2018; Lee et al. 2010; Mishra and Mishra 2018). In addition, Zhou et al. (2018) and Li et al. (2018) argue that the combination of the PCA-AHP methods can be optimal to eliminate the risk of dispertions in the AHP weighting system regarding the expert's judgements (Saaty and Vargas 2007). The literature examples present applications of both the PCA and AHP methods to deliver modelling results. The complementarity of both methods is discussed in the aforementioned studies.

Our mixed methods proposal is based on the existing and independent results obtained from the PCA and AHP analysis of the local competitiveness concept. Using the mixed method, we check the impact of the choice of weights structure for a model on a singular indicator. Thus, we run an experiment with weights modelling based on the use of a weights structure generated by one method and apply the weights values generated by the other. Since we employ a determined dataset of socioeconomic indicators, we present a new approach, not found yet in the PCA and AHP hybrid studies. The mixed model 1 (Mix 1) integrates the PCA-generated principal components structure and appoints the APHgenerated weights to the local competitiveness indicators. We reverse this concept in the mixed model 2 (Mix 2) using the AHP model structure and applying the PCA obtained weights values.

The weights of both procedures (Tables 2 and 3) are not directly comparable since they were generated in relation to the weighting assumptions of each method. Therefore, we normalize the generated weights in both methods. In this way, we obtain the weight of the indicator in relation to the entire model. The normalisation formula takes the form:

$$
w n_{i}=w C_{i} * w_{i} C_{i} i
$$

where 
Table 5 The mixed method no. 1 of local competitiveness model PCA weights structure based

\begin{tabular}{|c|c|c|c|c|c|c|c|}
\hline \multicolumn{8}{|c|}{ Principal components (PCA) } \\
\hline $\mathrm{wC} 1=0.29$ & $\mathrm{wC} 2=0.18$ & $\mathrm{wC} 3=0.17$ & $\mathrm{wC} 4=0.09$ & $\mathrm{wC} 5=0.09$ & $\mathrm{wC} 6=0.09$ & $\mathrm{wC7}=0.09$ & $\mathrm{wC} 8=0.08$ \\
\hline \multicolumn{8}{|c|}{ Indicators weights (AHP) } \\
\hline $\mathrm{wC}_{\mathrm{p}} 4=0.07$ & $\mathrm{wC}_{\mathrm{g}} 3=0.37$ & $\mathrm{wC}_{\mathrm{t}} 1=0.32$ & $\mathrm{wC}_{\mathrm{p}} 1=0.24$ & $\mathrm{wC}_{\mathrm{p}} 2=0.46$ & $\mathrm{wC}_{\mathrm{g}} 2=0.70$ & $\mathrm{wC}_{\mathrm{p}} 3=1$ & $\mathrm{wC}_{\mathrm{t}} 4=0.36$ \\
\hline $\mathrm{wC}_{\mathrm{e}} 1=0.18$ & $\mathrm{wC}_{1} 3=0.63$ & $\mathrm{wC}_{\mathrm{t}} 2=0.40$ & $\mathrm{wC}_{\mathrm{i}} 2=0.48$ & $\mathrm{wC}_{\mathrm{i}} 3=0.56$ & $\mathrm{wC}_{\mathrm{g}} 4=0.30$ & & $\mathrm{wC}_{\mathrm{i}} 1=0.33$ \\
\hline$w_{e} 2=0.16$ & & $w_{\mathrm{t}} 3=0.29$ & $\mathrm{wC}_{\mathrm{i}} 4=0.28$ & & & & $\mathrm{wC}_{1} 2=0.31$ \\
\hline \multicolumn{8}{|l|}{$\mathrm{wC}_{\mathrm{e}} 3=0.20$} \\
\hline \multicolumn{8}{|l|}{$w C_{e} 4=0.17$} \\
\hline \multicolumn{8}{|l|}{$\mathrm{wC}_{\mathrm{g}} 1=0.07$} \\
\hline \multicolumn{8}{|l|}{$\mathrm{wC}_{1} 1=0.07$} \\
\hline $\mathrm{wC}_{1} 4=0.07$ & & & & & & & \\
\hline
\end{tabular}

${ }^{*} w$-weight. source: own elaboration

Table 6 The mixed method no. 2 of local competitiveness model AHP weights structure based

Weights of categories (AHP)

${ }^{*} \mathrm{wC}_{\mathrm{p}}=0.14 \quad \mathrm{wC}_{\mathrm{e}}=0.24 \quad \mathrm{wC}_{\mathrm{g}}=0.12 \quad \mathrm{wC}_{\mathrm{t}}=0.17 \quad \mathrm{wC}_{\mathrm{i}}=0.19 \quad \mathrm{wC}_{\mathrm{l}}=0.14$

Factor loadings (PCA)

$\mathrm{wC}_{\mathrm{p}} 1=0.13 \quad \mathrm{wC}_{\mathrm{e}} 1=0.21 \quad \mathrm{wC}_{\mathrm{g}} 1=0.17 \quad \mathrm{wC}_{\mathrm{t}} 1=0.30 \quad \mathrm{wC}_{\mathrm{i}} 1=0.20 \quad \mathrm{wC}_{\mathrm{l}} 1=0.18$

$w_{\mathrm{p}} 2=0.34 \quad \mathrm{wC}_{\mathrm{e}} 2=0.25 \quad \mathrm{wC}_{\mathrm{g}} 2=0.21 \quad \mathrm{wC}_{\mathrm{t}} 2=0.26 \quad \mathrm{wC}_{\mathrm{i}} 2=0.20 \quad \mathrm{wC}_{\mathrm{l}} 2=0.13$

$w_{\mathrm{p}} 3=0.36 \quad \mathrm{wC}_{\mathrm{e}} 3=0.28 \quad \mathrm{wC}_{\mathrm{g}} 3=0.36 \quad \mathrm{wC}_{\mathrm{t}} 3=0.30 \quad \mathrm{wC}_{\mathrm{i}} 3=0.29 \quad \mathrm{wC}_{\mathrm{l}} 3=0.47$

$\mathrm{wC}_{\mathrm{p}} 4=0.17 \quad \mathrm{wC}_{\mathrm{e}} 4=0.26 \quad \mathrm{wC}_{\mathrm{g}} 4=0.26 \quad \mathrm{wC}_{\mathrm{t}} 4=0.14 \quad \mathrm{wC}_{\mathrm{i}} 4=0.31 \quad \mathrm{wC}_{\mathrm{l}} 4=0.22$

${ }^{*} w$-weight. source: own elaboration

$$
\sum_{i=1}^{n} w_{i}=1
$$

and

$$
\sum_{i=1}^{n} w_{i} i=1
$$

$w n$ - normalized weight. $w C_{i}$-weight of the PCA component or the AHP group. $w_{i} \mathrm{Ci}-$ weight of the PCA loading or the AHP subcategory. $i=1, \ldots, N$ (observation).

As a result of weights normalization, Table 5 and Table 6 illustrate the new mixed weights models according to the PCA and AHP model structures.

In the next steps we carry out the same procedure to obtain the local competitiveness indicator using the mixed model weights. The aggregation procedure (Formula 1) incorporates the Table 1 indicators according to the Table 5 and Table 6 weights structures. The mixed method number 1 and 2 competitiveness indexes for the observed batch of 63 municipalities are enclosed in the work of (Kurek 2020) together with the average index scores for each municipality. For the purpose of this article's nomenclature, the new indicators are labelled accordingly Mix 1 and Mix 2.

Next, the ranking and non-parametric correlations testing are repeated between the PCA, AHP and the two mixed methods local competitiveness indexes (Mix 1 and Mix 
Table 7 Cross tabs correlations calculation for the PCA, AHP and mixed methods no. 1 and no.2 local competitiveness indexes rankings

\begin{tabular}{lllll}
\hline & Value & $\begin{array}{l}\text { Asymptotic } \\
\text { Standard Error }^{\mathrm{a}}\end{array}$ & Approximate $^{\mathrm{b}}$ & $\begin{array}{l}\text { Approximate } \\
\text { Significance }\end{array}$ \\
\hline PCA-Mix 1 Ordinal by Ordinal & & & & \\
Kendall's tau-c & .862 & .030 & 28.386 & .000 \\
Gamma & .872 & .030 & 28.386 & .000 \\
Spearman Correlation & .960 & .016 & 26.788 & $.000^{\mathrm{c}}$ \\
AHP—Mix 1 Ordinal by Ordinal & & & & \\
Kendall's tau-c & .310 & .074 & 4.209 & .000 \\
Gamma & .316 & .075 & 4.209 & .000 \\
Spearman Correlation & .465 & .097 & 4.101 & $.000^{\mathrm{c}}$ \\
N of Valid Cases & 63 & & & \\
PCA-Mix 2 Ordinal by Ordinal & & & & .000 \\
Kendall's tau-c & .744 & .046 & 16.168 & .000 \\
Gamma & .751 & .046 & 16.168 & $.000^{\mathrm{c}}$ \\
Spearman Correlation & .893 & .037 & 15.494 & .000 \\
AHP—Mix 2 Ordinal by Ordinal & & & & .000 \\
Kendall's tau-c & .362 & .088 & 4.129 & $.000^{\mathrm{c}}$ \\
Gamma & .367 & .089 & 4.129 & \\
Spearman Correlation & .495 & .113 & 4.450 & \\
N of Valid Cases & 63 & & & \\
\hline
\end{tabular}

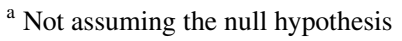

${ }^{\mathrm{b}}$ Using the asymptotic standard error assuming the null hypothesis

${ }^{\mathrm{c}}$ Based on normal approximation

source: SPSS stats 25 own elaboration

2). As previously, we use the average municipalities' rank position of the observed period 1995-2017. Results of four correlations testing are presented in Table 7.

Both tests reveal that the two rankings are significantly correlated. We observe that the appointed mixed weighting structure of either PCA or AHP contributes to the correlation results. The strong correlation is discovered between the PCA or AHP indexes and the mixed method index developed on the structure of one method. Therefore, a very high correlation coefficient results from the tests of the PCA local competitiveness indexes rankings, and the mixed method number 1 (Mix 1) indexes developed on the weights structure of the PCA (see Kurek 2020). A similar high correlation coefficient is observed when the AHP indexes rankings are examined against the mixed method number 2 (Mix 2), which is designed on the AHP weighting structure. Moreover, the comparable level of significant correlations is observed for the relationship between the PCA indexes rankings and the Mix 2, and the AHP indexes rankings and Mix 1 respectively. These results oscillate around a convergent value. Therefore, all of the local competitiveness index rankings yield positive and significant correlations. By analysing the correlations experiments, the strongest relationship is noticed between the PCA indexes rankings and the mixed method number 1 indexes that followed the PCA 
weights structure with the Spearman coefficient of 0,96 . This observation interprets the importance of the principal components in a multivariate indicators model.

The development of the mixed methods aimed to check the association between the PCA- and AHP-generated weights structures of local competitiveness models. The conducted correlations tests with the mixed models confirm that the local competitiveness rankings obtained by the PCA and AHP methods converge. Hence, the integration of the two multicriteria methods helps address the research question of this study. The significant relationship resulted from the correlation tests points out that the PCA and AHP methods deliver comparable results for the case of local competitiveness model design. The mixed methods experiment confirms this association through an observation of significant correlations scores between the PCA, AHP, and the mixed indexes rankings. The strongest relation is however observed between the PCA weights model and mixed weights model of the PCA structure.

\section{Conclusions and discussion}

In this paper, we ask whether in the case of a local competitiveness model based on data of the same socioeconomic indicators, the Principal Component Analysis (PCA) or Analytical Hierarchy Process (AHP) deliver comparable results. The research objective is motivated by understanding how the two methods, different in assumptions and procedures, operationalize a multivariate phenomenon such as local competitiveness. To analyze this problem, we take the example of two studies, Kurek et al. (2020a)- study 1 and Kurek et al. (2020b)- study 2, which used the same socioeconomic data to construct competitiveness models for a selection of municipalities in Poland. The data modelling based on the PCA and AHP weighting systems delivered the local competitiveness indexes for each of the observed municipalities for the years 1995-2017. We use index rankings to compare the scores of competitiveness. The municipalities' indexes rankings enable the non-parametric correlation test in order to answer the research question about the comparability of the local competitiveness models. The test rankings of the PCA and AHP local competitiveness indexes shows statistically significant results with the moderate magnitude of index correlation (Spearman's coefficient value 0,55). In this study, we ask if the results obtained using both methods deliver comparable knowledge about the phenomenon of local competitiveness. The results of the analysis observe a convergence of the phenomenon described by the AHP method and the same phenomenon developed using the PCA method. Therefore, both methods can be used to analyse the concept of local competitiveness for the dataset of the socioeconomic indicators.

We take a next step towards the comparison of the two methods and propose an integration of the weights system as a form of experimental testing. Although PCA- AHP hybrid methods exist in the literature, our novel approach lies in its practical application to the determined local socioeconomic indicators model. Integration of the two methods is based on applying the weights structure delivered by one method to the indicator weights given by the other method. As a result, we conducted two mixed weights modellings. This mixed approach addresses the issue of weights generation that are the determinants of the local competitiveness indexes scores.

The repeated non-parametric correlation tests for the PCA, AHP, and two mixed models demonstrate the significant associations between the local competitiveness indexes generated by all of the methods. Moreover, very strong correlations between the PCA, AHP, and 
the mixed methods local competitiveness indexes rankings indicate the robustness of the local development model itself. The highest magnitude of correlation is observed in the situation where the PCA indexes model is examined against the mixed model built on the PCA weights structure (Mix 1), and accordingly the AHP indexes model is tested against the AHP-structured mixed model (Mix 2). Therefore, the analysis of the correlation results illustrates the importance of the weights structure that is found to determine the results. The strongest correlation score resulted from the examination of the PCA indexes model and the mixed method indexes model built out of the PCA model structure. It supports the strength of PCA method in operationalization of a multivariate research problem that is based on coherent secondary data such the presented local competitiveness. The outcomes of our analysis underline the decisiveness of the weighting model structure. Although the correlations test of the AHP and mixed methods show significant results, the AHP applies a presumed structure in approaching a research problem. Theoretically, this can be the method's limitation since the experts follow a given model with judgements and assess the importance of the indicators in pairs, not influencing the relationship of the indicators outside the given pairs. In practice, the PCA method can have a technical advantage over the AHP in designing a multivariate model composed of coherent, numeric, and secondary data. It decides not only about the functional relationship between the indicators but also about the structure of these indicator's dependence.

As a result of the weights models experiment, all of the correlation results are positive and significant. The proposed experiment of mixed weights structures confirms the results of the PCA and AHP indexes rankings tests. The two methods are found to deliver comparable results in the situation of a determined research phenomenon like local competitiveness. The integration experiment showed the epistemic strength of the two methods. To conclude we argue that the decision about a choice of a multicriteria method is to be taken according to the specifics of the problems of the decision and the sort of data that describes it. Outcomes of our analysis refer to the Patton's $(1990,2002)$ paradigm of choices, where our proposed mixed approach supports the analysis of the best approach to a multicriteria concept of local competitiveness. From the observation of the PCA and AHP rankings correlations complemented by the mixed modelling of weights, we argue that the two multicriteria methods deliver convergent results. Nevertheless, following Patton's argument, the choice of a method should be guided by the type of data and the goal of the research problem. Since the proposed mixed method results are the closest to the PCA-obtained competitiveness indexes rankings and applying the Occam's razor principle, the simplest methodical solution should be applied in the situations of a comparable research problem. The Ockham razor resolves the heuristic problems that regard the choice between the simple and complex explanation, where both work equally well. Although both methods PCA and AHP deliver comparable results, the outcomes of mixed modelling point to the highest correlation scores with the PCA. Therefore, this method is advised for the analysis of a coherent and continuous dataset such as, in this case, the presented local competitiveness variables.

Funding No funding was received to conduct this study.

\section{Declarations}

Conflict of Interests The author declare that they heve no conflict of interest. 
Open Access This article is licensed under a Creative Commons Attribution 4.0 International License, which permits use, sharing, adaptation, distribution and reproduction in any medium or format, as long as you give appropriate credit to the original author(s) and the source, provide a link to the Creative Commons licence, and indicate if changes were made. The images or other third party material in this article are included in the article's Creative Commons licence, unless indicated otherwise in a credit line to the material. If material is not included in the article's Creative Commons licence and your intended use is not permitted by statutory regulation or exceeds the permitted use, you will need to obtain permission directly from the copyright holder. To view a copy of this licence, visit http://creativecommons.org/licenses/by/4.0/.

\section{References}

Abdi, H., Williams, L.J.: Principal component analysis. Wiley Interdiscip. Rev.: Comput. Stat 2(4), 433-459 (2010). https://doi.org/10.1002/wics.101

Abdi, H., Williams, L.J., Valentin, D.: Multiple factor analysis: principal component analysis for multitable and multiblock data sets. Wiley Interdiscip. Rev. Computat. Stat. 5(2), 149-179 (2013). https://doi.org/ 10.1002/wics. 1246

Alphonce, C.B.: Application of the analytic hierarchy process in agriculture in developing countries. Agric. Syst. 53(1), 97-112 (1997). https://doi.org/10.1016/S0308-521X(96)00035-2

Anderson, N.H.: Scales and statistics: parametric and nonparametric. Psychol. Bull. 58(4), 305 (1961). https://doi.org/10.1037/h0042576

Bagdonavicius, V., Kruopis, J., Nikulin, M.S.: Nonparametric tests for complete data. Wiley, New York (2013). https://doi.org/10.1002/9781118558072.app1

Boulanger, P.-M., Bréchet, T.: Models for policy-making in sustainable development: The state of the art and perspectives for research. Ecol. Econ. 55(3), 337-350 (2005). https://doi.org/10.1016/j.ecolecon. 2005.07.033

Bronisz, U., Heijman, W., Miszczuk, A.: Regional competitiveness in Poland: Creating an index. Jahrb. für Regionalwissenschaft 28(2), 133-143 (2008). https://doi.org/10.1007/s10037-008-0026-y

Bulu, M.: Measuring competitiveness of cities: Turkish experience. Int. J. Knowl. Based Dev. 2(3), 267-281 (2011). https://doi.org/10.1504/IJKBD.2011.042522

Bunge, M.: Epistemology of sociology. In: Smelser, N.J., Baltes, P.B. (eds.) International encyclopedia of the social and behavioral sciences, vol. 19, pp. 14569-14574. Elsevier, New York (2001)

Camagni, R., Capello, R.: Regional competitiveness and territorial capital: a conceptual approach and empirical evidence from the European Union. Reg. Stud. 47(9), 1383-1402 (2013). https://doi.org/10. 1080/00343404.2012.681640

Cox, A.M., Alwang, J., Johnson, T.G.: Local preferences for economic development outcomes: analytical hierarchy procedure. Growth Chang. 31(3), 341-366 (2000). https://doi.org/10.1111/0017-4815.00132

Dijkstra, L., Annoni, P., Kozovska, K.: (2011). A new regional competitiveness index: theory, methods and findings: European Commission. Directorate-General for Regional Policy.

Eskelinen, H., Hannibalsson, I., Malmberg, A., Maskell, P., Vatne, E.: Competitiveness, localised learning and regional development: specialization and prosperity in small open economies. Routledge, UK (2002)

Fabrigar, L.R., Wegener, D.T.: Exploratory factor analysis. Oxford University Press, Oxford (2011). https:// doi.org/10.1093/acprof:osob1/9780199734177.001.0001

Feng, X., Wen, Q.Q.: The research of evaluation for growth suitability of carya cathayensis sarg. Based on PCA and AHP. Procedia Eng. 15, 1879-1883 (2011). https://doi.org/10.1016/j.proeng.2011.08.350

Govaert, G.: Data analysis. Wiley, New York (2013)

Gross, S., Ringbeck, J.: Environmental Sustainability as a Driver for Competitiveness. Travel Tourism Competitiveness Rep. 2008, 27-40 (2008)

Hartwich, F.: Weighting of agricultural research results: Strength and limitations of the analytic hierarchy process (AHP). Universitat Hohenheim, Germany (1999)

Hoang, H.T., Truong, Q.H., Nguyen, A.T., Hens, L.: Multicriteria evaluation of tourism potential in the central highlands of vietnam: combining Geographic Information System (GIS), Analytic Hierarchy Process (AHP) and Principal Component Analysis (PCA). Sustain. 10(9), 3097 (2018). https://doi.org/ 10.3390/su10093097

Horton, D., Ballantyne, P., Peterson, W., Uribe, B., Gapasin, D., Sheridan, K.: Monitoring and evaluating agricultural research: a sourcebook. Cab International, England (1993)

Huggins, R.: Creating a UK competitiveness index: regional and local benchmarking. Reg. Stud. 37(1), 89-96 (2003). https://doi.org/10.1080/0034340022000033420 
Huovari, J., Kangasharju, A., Alanen, A.: Constructing an index for regional competitiveness. In: Acs, Z.J., de Groot, H.L.F., Nijkamp, P. (eds.) The emergence of the knowledge economy. Advances in spatial science. Springer, Berlin, Heidelberg (2002). https://doi.org/10.1007/978-3-540-24823-1_7

Ishizaka, A., Labib, A.: Analytic hierarchy process and expert choice: Benefits and limitations. Or Insight 22(4), 201-220 (2009)

Jolliffe, I.T.: Principal components in regression analysis Principal component analysis, pp. 129-155. Springer, Berlin (1986)

Johnson, R.B., Onwuegbuzie, A.J.: Mixed methods research: a research paradigm whose time has come. Educ. Res. 33(7), 14-26 (2004). https://doi.org/10.3102/0013189X033007014

Kil, S.-H., Lee, D.K., Kim, J.-H., Li, M.-H., Newman, G.: Utilizing the analytic hierarchy process to establish weighted values for evaluating the stability of slope revegetation based on hydroseeding applications in South Korea. Sustain. 8(1), 58 (2016). https://doi.org/10.3390/su8010058

Kim, J.-O., Mueller, C.W.: (1978). Introduction to factor analysis: what it is and how to do it. In: Series: quantitative applications in social sciences. Sage University Paper No 07-013. Sage Publications, Inc

Komac, M.: A landslide susceptibility model using the analytical hierarchy process method and multivariate statistics in perialpine Slovenia. Geomorphol. 74(1-4), 17-28 (2006). https://doi.org/10.1016/j.geomo rph.2005.07.005

Kukula, K., Bogocz, D.: (2014). Zero unitarization method and its application in ranking research in agriculture. Econ. Reg. Stud. (Studia Ekonomiczne i Regionalne) 7, 5-13. https://doi.org/10.22004/ag. econ.265035

Kurek, K.A.: Dataset for: Measuring local competitiveness: comparing and integrating two methods PCA and AHP. Mendeley Data V2, (2020). https://doi.org/10.17632/z72tgw2phx.2

Kurek, K.A., Heijman, W., van Ophem, J., Gędek, S., Strojny, J.: The impact of geothermal resources on the competitiveness of municipalities: evidence from Poland. Renew. Energy 151, 1230-1239 (2020a). https://doi.org/10.1016/j.renene.2019.11.126

Kurek, K.A., Heijman, W., van Ophem, J., Gędek, S., Strojny, J.: Geothermal spas as a local development factor, the case of Poland. Geothermics 85, 101777 (2020b). https://doi.org/10.1016/j.geothermics. 2019.101777

Kurek, K.A., Heijman, W., van Ophem, J., Gędek, S., Strojny, J.: Dataset for the model of municipality competitiveness in relation to the geothermal resources exploitation in Poland. Mendeley Data V2, (2020c). https://doi.org/10.17632/zfndmn3f55.2

Lee, J., Kang, S.-H., Rosenberger, J., Kim, S.B.: A hybrid approach of goal programming for weapon systems selection. Comput. Ind. Eng. 58(3), 521-527 (2010). https://doi.org/10.1016/j.cie.2009.11.013

Lengyel, I., Rechnitzer, J.: The competitiveness of regions in the Central European transition countries. Macrotheme Rev. 2(4), 106-121 (2013)

Li, X., Lu, J., Gao, Z., Yang, Y.: (2018). Effectiveness evaluation of kill chain based on PCA, AHP and entropy weight method. Paper presented at the 2018 3rd International conference on modelling, simulation and applied mathematics (MSAM 2018). https://doi.org/10.2991/msam-18.2018.41

Linkov, I., Moberg, E.: Multi-criteria decision analysis: environmental applications and case studies. CRC Press, USA (2011)

Macharis, C., Springael, J., De Brucker, K., Verbeke, A.: PROMETHEE and AHP: The design of operational synergies in multicriteria analysis.: Strengthening PROMETHEE with ideas of AHP. Eur. J. Oper. Res. 153(2), 307-317 (2004). https://doi.org/10.1016/S0377-2217(03)00153-X

Makštutis, A., Balkytė, A., Tumalavičius, V.: Security, Sustainability and Competitiveness: Benchmarking Attempts. J. Secur Sustain. Issues 2(1), 5-12 (2012)

Malecki, E.: Jockeying for position: what it means and why it matters to regional development policy when places compete. Reg. Stud. 38(9), 1101-1120 (2004). https://doi.org/10.1080/0034340042 000292665

Maletič, D., Lasrado, F., Maletič, M., Gomišček, B.: Analytic hierarchy process application in different organisational settings. Appl. Theory Anal. Hierarchy Process: Decis. Mak. Strateg. Decis. (2016). https://doi.org/10.5772/64511

Mason, J.: Mixing methods in a qualitatively driven way. Qual. Res. 6(1), 9-25 (2006). https://doi.org/ $10.1177 / 1468794106058866$

Mishra, R., Mishra, O.N.: A hybrid PCA-AHP-Multi-grade Fuzzy approach to assess marketing-based flexibility. Mark. Intell. Plan. (2018). https://doi.org/10.1108/MIP-07-2017-0144

Oddershede, A., Arias, A., Cancino, H.: Rural development decision support using the Analytic Hierarchy Process. Math. Comput. Model. 46(7-8), 1107-1114 (2007). https://doi.org/10.1016/j.mcm. 2007.03.006

Olewiler, N.: Environmental sustainability for urban areas: The role of natural capital indicators. Cities 23(3), 184-195 (2006). https://doi.org/10.1016/j.cities.2006.03.006 
Ozaslan, M., Dincer, B., Ozgur, H.: Regional disparities and territorial indicators in Turkey: socio-economic development index (SEDI). Conference paper. 46th Congress of the European Regional Science Association-Enlargement, Southern Europe and Mediterranean, Greece (2006).

Palei, T.: Assessing the impact of infrastructure on economic growth and global competitiveness. Procedia Econ. Financ. 23(2015), 168-175 (2015). https://doi.org/10.1016/S2212-5671(15)00322-6

Palese, L.L.: A random version of principal component analysis in data clustering. Comput. Biol. Chem. 73, 57-64 (2018). https://doi.org/10.1016/j.compbiolchem.2018.01.009

Patton, M.Q.: Qualitative evaluation and research methods. SAGE Publications inc, New York (1990)

Patton, M.Q.: Two decades of developments in qualitative inquiry: a personal, experiential perspective. Qual. Soc. Work. 1(3), 261-283 (2002). https://doi.org/10.1177/1473325002001003636

Pawluszek, K., Borkowski, A.: Impact of DEM-derived factors and analytical hierarchy process on landslide susceptibility mapping in the region of Rożnów Lake. Poland. Nat. Hazards 86(2), 919-952 (2017). https://doi.org/10.1007/s11069-016-2725-y

Pires, S.M., Fidélis, T., Ramos, T.B.: Measuring and comparing local sustainable development through common indicators: Constraints and achievements in practice. Cities 39, 1-9 (2014). https://doi. org/10.1016/j.cities.2014.02.003

Plummer, P., Tonts, M., Martinus, K.: Endogenous growth, local competitiveness and regional development: Western Australia's Regional Cities, 2001-2011. J. Econ. Soc. Policy 16(1), 146 (2014)

Porter, M.E.: Building the microeconomic foundations of prosperity: Findings from the business competitiveness index. Global Compet. Rep. 2004, 29-56 (2003)

Porter, M.E.: Regional competitiveness in a global economy. Conference paper. The summit for American prosperity the brookings institution Washington, D.C June 11, 2008 (2008)

Rutkauskas, A.V.: On the sustainability of regional competitiveness development considering risk. Technol. Econ. Dev. Econ. 14(1), 89-99 (2008). https://doi.org/10.3846/2029-0187.2008.14.89-99

Saaty, T.L.: What is the analytic hierarchy process? Mathematical models for decision support, pp. 109121. Springer, Berlin (1988)

Saaty, T.L.: Fundamentals of decision making and priority theory with the analytic hierarchy process, vol. 6. RWS publications, Pittsburgh (2000)

Saaty, T.L., Vargas, L.G.: Dispersion of group judgments. Math. Comput. Model. 46(7-8), 918-925 (2007). https://doi.org/10.1016/j.mcm.2007.03.004

Sáez, L., Periáñez, I.: Benchmarking urban competitiveness in Europe to attract investment. Cities 48, 76-85 (2015). https://doi.org/10.1016/j.cities.2015.06.002

Scipioni, A., Mazzi, A., Mason, M., Manzardo, A.: The Dashboard of Sustainability to measure the local urban sustainable development: the case study of Padua Municipality. Ecol. Ind. 9(2), 364-380 (2009). https://doi.org/10.1016/j.ecolind.2008.05.002

Sharp, J.L., Mobley, C., Hammond, C., Withington, C., Drew, S., Stringfield, S., Stipanovic, N.: A mixed methods sampling methodology for a multisite case study. J. Mixed Methods Res. 6(1), 34-54 (2012). https://doi.org/10.1177/1558689811417133

Shi, H.: Applying principal component analysis and group-decision analytical hierarchy process for the fuzzy risk assessment of construction project. Adv. Sci. Lett. 6(1), 779-782 (2012). https://doi.org/ 10.1166/asl.2012.2264

Siegel, S.: Nonparametric statistics. Am. Stat. 11(3), 13-19 (1957)

Siegel, S., Castellan, N.: The case of k related samples, pp. 170-174. McGraw-Hill, Nonparametric statistics for behavioral sciences. New York (1988)

Storper, M.: The regional world: territorial development in a global economy. Guilford press, New York (1997)

Strojny, J.: Implementation of the AHP and benchmarking in Strategic Analysis of Polish Regions. ProcSoc. Behav. Sci. 213, 229-235 (2015). https://doi.org/10.1016/j.sbspro.2015.11.530

Strojny, J., Hejman, W.: AHP based multicriteria comparative analysis of regions of eastern Poland. Int J Anal Hierarchy Process 8(1), (2016). https://doi.org/10.13033/ijahp.v8i1.373

Subbaiah, K.V., Prasad, K., Bharathi, M.U., Rao, K., Sekhara, S.: Integrating factor analysis and analytic hierarchy process for library service quality. Int. J. Qual. Res. 5(3), 205-212 (2011)

Subramanian, N., Ramanathan, R.: A review of applications of Analytic Hierarchy Process in operations management. Int. J. Prod. Econ. 138(2), 215-241 (2012). https://doi.org/10.1016/j.ijpe.2012.03.036

Taherdoost, H., Sahibuddin, S., Jalaliyoon, N.: Exploratory factor analysis; concepts and theory. Adv. Appl. Pure Math. 27, 375-382 (2014)

Tashakkori, A., Teddlie, C.: Handbook of mixed methods in social and behavioral research. Sage, California, US (2010) 
Tee, S., Liu, Q., Wang, Z.: Insulation condition ranking of transformers through principal component analysis and analytic hierarchy process. IET Gener. Transm. Distrib. 11(1), 110-117 (2017). https://doi.org/ 10.1049/iet-gtd.2016.0589

Trisnawati, R., Wiyadi, W., Priyono, E.: Analysis of the competitiveness tourism industries increasing the local economy (The comparative study analysis of the competitiveness tourism between Surakarta and Yogyakarta). Econ. J. Emerg. Mark. 13(2) (2008). https://doi.org/10.20885/vol13iss2aa489

Vyas, S., Kumaranayake, L.: Constructing socio-economic status indices: how to use principal components analysis. Health Policy Plan. 21(6), 459-468 (2006). https://doi.org/10.1093/heapol/czl029

Publisher's Note Springer Nature remains neutral with regard to jurisdictional claims in published maps and institutional affiliations. 